\title{
LA COPIA FELIZ DEL EDÉN LA GLORIA DE UN HIMNO Y EL DESGARRO DEL POEMA
}

\author{
Rodrigo Karmy Bolton \\ Universidad de Chile \\ rkarmy@gmail.com \\ "Y creó Dios a imagen suya: \\ a imagen de Dios le creó (...)" \\ Génesis 1,27
}

Resumen

El presente texto se interroga sobre los efectos performativos del himno de Chile en cuanto éste designa al país en la forma de una "copia feliz del Edén". A partir de ahí, se pregunta ¿cómo podría una copia afirmarse en la originalidad de una soberanía? Para solucionar la distancia entre copia y original y, por tanto, dar lugar al funcionamiento de la soberanía, el himno designa a esa copia como "feliz". El término "feliz" se constituye, así, en el operador que vendría tanto a apuntalar a la constitución de una soberanía como a revelar el límite de su imposibilidad. "Feliz" permite disminuir la distancia entre copia y original, pero a la vez, la conserva irremediablemente. Por eso, decir que el país es la copia "feliz" es lo mismo que decir "infeliz" toda vez que ambos términos no hacen más que corroborar la diferencia ontológica entre copia y original. Se argumenta que el término "feliz" constituye un dispositivo teológico-político, toda vez que replica la función angélica destinada a la administración de la creación divina. En estos términos se pregunta: ¿no será el proyecto de la República de Chile un proyecto esencialmente administrativo? A esta luz, el texto plantea la contraposición entre himno con el poema: el himno -se plantea- constituye el operador angélico que hace posible la articulación de una soberanía. El poema, en cambio, constituiría el resto irreductible que le resiste.

PALABRAS CLAVE: soberanía, ángel, himno, poema.

\section{Abstract}

This essay asks on the performative efects of the chilean hymn, because it names the country as a "happy copy of Eden". Since this problem, the essay asks: how could the copy may posits as the originality of the sovereignity? To solve the distance between the copy and the original and make posible the sovereignity's operation, the hymn names the copy as "happy". The word "happy" supports the constitution of the sovereignity and reveals the limit of its own imposibility. "Happy" reduce the distance between the copy and the original but, at the same time, absolutely preserve it. That's why, say that the country is the "happy" copy is the same than to say that is a "unhappy" one, because both words (happy and unhappy) shows the ontological difference between the copy and the original. This essay argues that the word "happy" is a political theological device because repeats the angelical task of manage the divine creation. In theses terms we ask: ¿Is the chilean republican proyect an administrative one? In this light, the essay posits 
an aporia between the hymn and poem: the hymn constitutes the angelical operator that makes sovereignity posible, the poem constitutes a singular rest that resist it.

KEY WORDS: sovereignity, angel, hymn, poem.

RA 1. El himno de Chile inicia con los siguientes versos: "Puro Chile es tu cielo azulado, puras brisas te cruzan también, y tu campo de flores bordados, es la copia feliz del Edén". Toda copia es siempre la imagen trunca de un original. La copia lleva consigo fallas que el original supuestamente no lleva. La copia es tal, solo porque está desplazada respecto del original. A la inversa, el original es tal precisamente porque constituye el referente de la copia. Se podría decir que, en este sentido, la copia es siempre una representación del original. El original funda una representación en la forma de una copia y, por tanto, la relación que ambos establecen se estructura en una jerarquía, esto es, una relación que se mide por la diferencia de un poder ${ }^{1}$.

¿Que implicará que un país se autodesigne en la forma de una copia? Nótese que, desde ya, dicha operación es del todo paradójica: si alguien es capaz de autodesignarse es precisamente porque no es una copia, en tanto se desenvuelve soberanamente en la forma de un original. Pero ¿como puede una copia ejercer por lo tanto una soberanía, autodesignarse en la forma de una copia? Como si la soberanía jugara en contra de sí misma desprendiéndose en su propio acto de constitución y como si los versos "la copia feliz del Edén" dejaran entrever la imposibilidad intrínseca de una soberanía para constituirse como tal. Es en este contexto donde al adjetivo "feliz" hace su ingreso para funcionar como un verdadero operador que intenta investir del aura del original a la copia que por definición no lo tiene. En otras palabras, el término "feliz" vendría a apuntalar tanto a la constitución de una soberanía, como a revelar el límite de su imposibilidad.

En la medida en que dicho verso se presenta como un intento de traspasar la autoridad del original a la sujeción de la copia, éste vendría a estructurar una suerte de jerarquía compuesta por la "copia" que correspondería a los hombres, lo "feliz" que correspondería a los ángeles, y el "Edén" que correspondería a Dios. Hombres,

1 Es importante señalar que el término "jerarquía" aparece por primera vez en el PseudoDionisio. Mas tarde, Tomás de Aquino comentará dicho término de modo certero señalando que "jerarquía" designará a un "poder sacro". Sin embargo, no es un poder sagrado, en el sentido de que éste constituiría un poder originariamente profano que posteriormente se sacraliza a partir de algún discurso religioso que vendría a legitimarle, sino más bien, por la misma estructura del poder soberano que, en su capacidad excepcionalista, se revela en sí mismo como un poder sacro. En este sentido, el término jerarquía lo utilizamos en su estricto sentido teológico-político. Véase Giorgio Agamben y Emanuele Coccia (eds.), 2009. 
ángeles y Dios constituirían, pues, el triunvirato de una jerarquía cuyo ejercicio estará articulado en la función propiamente angelológica del adjetivo "feliz" que, por serlo, deberá comunicar los dos órdenes antedichos para dar curso a la maquinaria del poder. Con ello, el motor de dicha maquinaria operará a través de dicho adjetivo que, una y otra vez, tendrá que hacer todo lo posible para que esa copia se acerque lo más posible a la soberanía del original.

Pero, dicha operación se fundará, esencialmente, sobre una imposibilidad: su ejercicio no solo no puede nunca coincidir enteramente consigo mismo, puesto que no podrá suturar definitivamente la diferencia ontológica entre la copia y el original. Por ello, la operación del adjetivo "feliz" como articulador angelológico ha de ser vista como radicalmente paradójica: debe articular dos órdenes ontológicamente heterogéneos sin nunca poder lograrlo del todo. De esta manera, si la soberanía de Dios opera separando la copia del original, la administración de los ángeles se orientará en función de su comunicación.

En los dos órdenes antedichos (la copia y el Edén) habría que leer dos racionalidades específicas del poder: la racionalidad de la soberanía afincada en la dimensión estatalmilitar y la racionalidad del gobierno estructurada en el carácter económico-gestional del poder. Todo el problema residirá en cómo estas dos racionalidades podrán articularse entre sí. La tesis que quisiera sostener aquí es que dicha articulación será posible en la medida en que los versos hímnicos introducen el adjetivo "feliz" como su operador fundamental, su vaso comunicante.

Solo porque se introduce dicho operador los dos mundos, aquél de la copia y aquél del Edén, darán lugar a un dispositivo constituido por la bipolaridad entre el paradigma económico-gestional (la copia) y el paradigma estatal-militar del poder (el Edén). La clave aquí es, sin embargo, que ambas racionalidades solo pueden funcionar en la medida en que introducen dicho operador, lo cual implica que éstas no pre-existen a la operación del adjetivo "feliz", sino que solo cobran existencia a partir de él, solo a partir de su relación. Sin éste, la tierra y el cielo, la economía y la soberanía no lograrían nunca articularse entre sí. Por ello, el adjetivo "feliz" cumplirá la función angelológica de la comunicación entre los dos mundos, sin la cual ambos quedarían completamente inoperantes. En esta perspectiva, quizás habría que situar la transformación de la casa de la Moneda en el palacio presidencial, como la metáfora más prístina de dicha articulación.

En razón de ello, sostenemos que los versos que caracterizan a Chile como una “copia feliz del Edén" inscriben al país como un proyecto esencialmente económicogestional. Así, la copia podrá ser "feliz" solo si se presenta como "reflejo" del orden divino de la soberanía, es decir, como un orden preconstituido, es decir, sagrado. A esta luz, el reciente discurso de la economía política neoliberal encontraría su condición de posibilidad en la estructura de los versos hímnicos que caracterizan a Chile como una "copia feliz del Edén": siendo "feliz", el orden sobre el cual se funda dicha copia no podrá sino ser "sagrado", lo cual implicará aparecer como un orden preconstituido e inmodificable, cuya secularización se expresará en la figura del "orden natural". Con ello, el orden económico neoliberal podrá presentarse como un dispositivo de 
veridicción que, como tal, determinará si el ejercicio del poder estatal será bueno o malo, verdadero o falso situando, a su vez, a dicha economía como la única teología que parece haber sobrevivido a la muerte de Dios². Sin embargo, el término "teología" aquí no designaría a cualquier discurso religioso de carácter confesional, sino a todo aquél capaz de garantizar el orden en la medida en que hace coincidir al pensamiento con la ley de la ciudad ${ }^{3}$.

En la medida en que el discurso neoliberal pueda ser comprendido como una teología que sitúa a un orden inmanente (la copia) en la forma de un reflejo de la perfección de la norma trascendente (el Edén), el orden que dicho discurso funda no podrá sino proyectarse como un orden "dado" e inmodificable, cuya figura última será la de la economía neoliberal en que el "orden divino" se seculariza como "orden natural”. A fines de los años 70 éste será precisamente el problema de Jaime Guzmán a la hora de elaborar la Constitución de 1980 actualmente vigente cuya resolución se encontrará en el diseño de una democracia constituida por dos pilares básicos: la libertad y la autoridad o, si se prefieren, entre la "copia feliz" y el "Edén" de la propia máquina de la soberanía ${ }^{4}$.

En este sentido, el punto de cruce entre ambas racionalidades (entre la copia y el Edén, entre el gobierno y la soberanía, respectivamente) ha de encontrarse en dos figuras que sobredeterminan decisivamente a toda la historia de la República, en la medida en que actúan como las bisagras entre ambas racionalidades, entre la copia y el Edén: Portales, el comerciante que se convierte en ministro de Estado, y Pinochet, el jefe de Estado que salva a los comerciantes. Dos tiempos de un mismo dispositivo: ¿Qué más evidente que estas dos figuras de nuestra historia para medir la potencia histórica del himno?

2 Michel Foucault escribe: “A mediados del siglo XVIII se hizo evidente que el mercado ya no era el lugar de jurisdicción o, más bien, ya no debía serlo. Y se dejó ver entonces, por una parte, como algo que obedecía y debía obedecer a mecanismos "naturales" (...) El mercado, en la medida en que a través del intercambio permite vincular la producción, la necesidad, la oferta, la demanda, el valor, el precio, etc. , constituye un lugar de veridicción, y con ello, quiero decir, un lugar de verificación y falseamiento de la práctica gubernamental". Michel Foucault 2007, pp. 48-49. De esta forma, la "veridicción" constituye un dispositivo capaz de determinar si una determinada práctica gubernamental es verdadera o falsa o, lo que es igual, si dicha práctica será o no legítima desde la perspectiva del mercado.

Emanuele Coccia 2008.

4 Renato Cristi 2000. Asimismo, será preciso recordar que, siguiendo esta misma vía, para Foucault el problema de la soberanía se retoma en 1979, ahora para pensar en las formas de ejercicio del gobierno o, lo que es igual, que la gubernamentalidad neoliberal será una forma de ejercicio de la soberanía política, por lo cual habría que insistir en la coherencia interna, en la articulación entre las dos racionalidades del poder. En: Michel Foucault, op. cit., p. 17. 
2.- "Himno" no refiere aquí a una simple representación ya dada, sino a un dispositivo que produce la articulación "feliz" entre el original y la copia, entre Dios y los hombres. En este sentido, entenderemos que el himno constituye un dispositivo glorificante que, como tal, hace posible la "promiscuidad" entre dos órdenes de existencia: el teológico, donde habita Dios y su Edén, y el político, donde habitan los hombres y sus pecados 5 . En razón de tal operación, la singularidad del himno consistiría en la transformación del lenguaje desde su carácter referencial (consistente en indicar una realidad exterior a sí mismo) a su carácter performativo (donde palabra y acción coinciden sin fisuras).

Así, el himno constituiría la función que haría de esta "copia” una "copia feliz" en la medida en que, al glorificar a aquello que, por definición carece de gloria (la copia), hace posible su inscripción en el régimen de la soberanía. Por ello, el himno vendría a glorificar al poder toda vez que éste no es otra cosa que esa misma performance glorificante. Así, será el himno el dispositivo que articula los signos, aclama a sus héroes y enciende los corazones, expandiendo la luz de Dios sobre la oscuridad de la tierra.

En este sentido, la performatividad hímnica consistirá en la producción de una soberanía. Por ello, el himno no deberá ser considerado un mero "velo" ideológico, sino la arqui-tectura misma de la soberanía o incluso, a la soberanía como la misma arqui-tectura del himno, a través de cuya performatividad logran articularse las dos racionalidades del poder.

A esta luz, habrá que diferenciar al himno del poema. Porque si, como hemos visto, el primero glorifica articulando al original con su copia, a Dios con el mundo, el poema hace todo lo contrario: separa, abre, tensiona. Así, lo que el himno totaliza, el poema singulariza, lo que el himno clausura, el poema abre, lo que el himno convierte en el cuerpo de una soberanía (la articulación de un signo), el poema desgarra la carne de un impoder (la dispersión de una a-significancia). Siendo el himno el dispositivo que hace funcionar una soberanía, el poema se vuelca como aquella palabra que interrumpe dicho funcionamiento.

Quizás en esta perspectiva deba ser vista la compleja relación de los poetas chilenos con su República, precisamente. Casi todos comparten el hecho de haber nacido o vivido en los márgenes de la ciudad, casi todos comparten el hecho de haber tenido una complicada relación con los gobiernos de turno. Porque si el himno funciona en razón de suturar la distancia entre el original y la copia, entre el Edén y la República, el poema trabaja exactamente en sentido contrario: abre esa distancia hasta el punto donde el original y la copia se disuelven sin remedio. Así, si en el himno el lenguaje es capturado por la soberanía de un autor, en cambio, en el poema el lenguaje es restituido a su ser común, lejos de cualquier soberanía. Por eso quizás podemos decir que así como el himno es, fundamentalmente, el canto de la soberanía, el poema sería, en este sentido, el eco de los perdidos. 
Sin embargo ¿ha podido un himno coincidir con un poema, ha podido un poema caber en el funcionamiento de un himno? Quizás sea interesante pensar la experiencia de la Unidad Popular en función de esta exigencia: la poesía proyectándose en la forma de un himno, y el himno abriéndose al modo de una poesía. ¿No sería ésta la estrecha complicidad entre Allende y Neruda, el político y el poeta, la praxis y la poiesis? Pero en este caso ¿quién sería el poeta, quién el político, el que canta una Elegía a Stalingrado o quien dirige sus últimas palabras a través de radio Magallanes? Quizás, la potencia de la Unidad Popular haya estado en haber ejercido el movimiento inverso al del himno: si este último habría operado en la forma de una máquina de la soberanía capaz de transformar el poema en un himno, la Unidad Popular, en cambio, habría sido la irrupción del poema en función de su completa desarticulación.

3.- En el horizonte de la "copia feliz del Edén" cobra sentido la idea chilensis acerca de la "excepcionalidad", según la cual, dentro del concierto latinoamericano Chile sería un país "excepcional" respecto de los demás. Como bien ha indicado García de la Huerta, ha sido en el pasado reciente que esa idea ha atravesado tanto a izquierdas como a derechas: las izquierdas con la llegada al poder de la Unidad Popular por la "vía democrática", calificada de "experiencia única" en el mundo, y las derechas, con la instalación de Chile en la vanguardia mundial del neoliberalismo y la consecuente derrota del "comunismo".

Curioso narcisismo criollo que se resuelve en la misma paradoja que habíamos indicado antes: ¿cómo es que un país cuyo himno asigna el estatuto de "copia” puede ser un país "excepcional"? La respuesta reside en el adjetivo "feliz", que funciona como el operador discursivo esencial que tendrá por función la de investir a la copia con el aura de la divinidad propia del original. Porque ¿cómo es que los "copiones" podrían eventualmente llegar a ser "excepcionales" sino es a través de la comunicatio idiomatum que establece el adjetivo "feliz"? ¿QQué efectos llega a producir el adjetivo "feliz" sino el de suturar las fallas de la copia, invistiendo a ésta del aura necesaria para elevarse de entre las demás "copias" que habitan en el continente?

Para realzar la elevación de la copia al original se requiere de la violencia suprema de la soberanía que, sin embargo, en la imposibilidad de aprehender el original revelará su carácter ficcional". "Ficción" aquí no indica un mero velo ideológico que viene a ocultar una determinada realidad, sino más bien, a la performance de dicha violencia que, en el conjunto de sus operaciones (epistémicas, discursivas y políticas), vendría a fundar a la propia soberanía.

En efecto, glorificarse de ser una copia comporta una seria desventaja, a saber, que una copia no puede nunca pertenecer absolutamente al terreno de la mismidad

Marcos García de la Huerta 2003.

Phillipe Lacoue-Labarthe 2002. 
del original. La copia es siempre una "alteridad", nunca una "mismidad". En este caso, solo el original sería "excepcional” y, como tal, solo el original vendría a pertenecer al ámbito del "ser" propiamente. Dicho de otro modo: solo el original puede "ser", la copia, por definición, nunca "es". Pero si la copia no puede "ser", entonces ¿cuál será su ámbito? El ámbito de la copia será, esencialmente, aquél que pertenece a un "orden" (jerarquía) que, como tal, se presentará siempre como el reflejo de un "ser" (Dios). Así, la copia siempre será insustancial, a diferencia de la sustancia que definirá al original. Por eso, la copia no tiene, en este sentido, una tierra firme: ¿qué más podría ocurrir en un país esencialmente sísmico como Chile, donde la tierra firme, es decir, la "propiedad", es justamente lo que siempre está en cuestión, ya sea por la irrupción mapuche, ya sea por los continuos terremotos? ¿Qué implicará no tener una tierra firme en un país que basa la casi totalidad de su economía en la minería? ¿Cuán firme sería, entonces, esa tierra o, lo que es igual, cuán original podrá ser dicha copia?

Hemos dicho que la copia refiere al plano de un "orden" no de un "ser". Como tal, se inscribe en el marco de una jerarquía, esto es, en medio de un poder originariamente sagrado que establece rangos diferenciados en relación con el original. Así, el hecho de que la copia refiera al problema del "orden" y no al del "ser" implica que ésta no tiene nunca garantizada su aura, su intensidad con el original. Dicho en el lenguaje angelológico cristiano: como sucedió con el demonio, en cualquier momento se puede suscitar su "caída". Es por ello que en cuanto copia, la relación con el original ha de ser permanentemente actualizada por medio de la incondicionada glorificación proveída por el término "feliz".

El peligro de la caída testimonia que la distancia que separa a la copia del original indica que, a diferencia de éste, constituido en y por su propio fundamento, la copia se inscribirá en un orden jerárquico que implicará que ésta se halle infundamentada o, más exactamente, que ésta nunca encuentre su fundamento en sí misma. Así, en la medida en que la copia está siempre dislocada del fundamento, ésta debe hacer un esfuerzo por alcanzarle y mantener su aura viva. Por esta razón, la copia puede ser siempre "aspirante" al original, pero nunca ser el original mismo ${ }^{8}$.

Por ello, las implicancias de que la copia pertenezca al ámbito de un "orden” y no al de un "ser" implica que ésta se resuelva en la forma gubernamental del "deber" (es decir, una praxis orientada a un fin específico). Así, en cuanto "feliz del Edén" la copia adquiere como único "ser" su "deber". Por eso, en la medida en que su estatus no está ontológicamente garantizado, sino solo jerárquicamente establecido, la copia mide su altura por la excelencia de su eficacia que no es otra cosa que la violencia de su ficción.

8 El incesante esfuerzo por alcanzar el "original" configura lo que el propio Foucault denominó “Razón de Estado", es decir, ese ejercicio del poder gubernamental cuyo objetivo es radicalmente inmanente en la medida en que no hace más que aumentarse y extenderse a sí mismo una y otra vez. Véase Michel Foucault 2006. 
Quizás sea en la distancia entre copia y original, entre deber ser y ser donde se juegue toda la ficción de la soberanía y de la soberanía como ficción, es decir, el intento de la soberanía por apropiarse del instante revela, a su vez, la imposibilidad de coincidir enteramente con éste. Por este motivo, el conflicto entre copia y Edén es, en el fondo, el conflicto que constituye la estructura de la propia soberanía, a saber: que la decisión por fundar un original está temporalmente desgarrada de sí misma.

Dicho de otra forma: la soberanía nunca puede ser "sí misma" completa y absolutamente, toda vez que al ficcionar al instante ésta no deja de diferirlo. Es por ello que los versos "la copia feliz del Edén" tendrán que introducir el adjetivo "feliz" como su operador para, hasta donde sea posible, suturar la diferición temporal inmanente a toda soberanía. Pero, como hemos visto, ello nunca se logra plenamente. Así, habrá un remanente a la soberanía que el adjetivo "feliz" intentará capturar. En otras palabras, la soberanía se presentará, pues, como un imposible, toda vez que ésta nunca podrá clausurar totalmente el espacio de la vida. ¿Qué hacer, entonces, con ese resto, aquello que llamaremos poema, que resiste a su incorporación hímnica, al modo de un remanente de soberanía?

La paradoja de querer ser un original siendo una copia se traduce a lo largo de la historia republicana en la adopción de diversos proyectos políticos que, al realizarse, exigen la fundación de un original, al punto de experimentar la inmensa desventura de verse a sí mismos como una copia. La violencia de la fundación se consuma, pues, en la melancolía de su proyección. Así, pues, ¿acaso no podemos leer nuestra historia republicana a la luz de esta paradoja, considerando los avatares de la república como el intento indiscriminado de acabar con dicho remanente para imponer un proyecto "original" y absolutamente "puro"? De hecho, Puro Chile son las dos primeras palabras del himno que, en su proceso de glorificación, será caracterizado en la forma de la copia feliz del Edén: una copia podrá aspirar a ser "pura" si y solo si ésta lleva consigo el dispositivo "feliz" que la inviste del aura de la soberanía.

De ahí que, cuando en 1973 las FF.AA. ejecutan el golpe de Estado, el discurso del general Leigh se proyecte en función de la restauración del himno apelando al "cáncer marxista" que, como todo poema, no habría hecho más que corroer la supuesta pureza de la nación. El movimiento que restaura la arquitectura del himno habría implicado la restitución de la metáfora de Chile como un cuerpo político absolutamente original, sin mancha, sin restos y, por lo tanto, sin indicio alguno del poema9. Como si la hipérbole de la toma del poder por parte de la Junta Militar hiciera posible al "puro" Chile y prometiera así, la eterna "felicidad" de la copia.

4.- Sin embargo, en toda copia persiste un problema: por más "feliz del Edén" que ésta sea, siempre lleva consigo "algo" cuyo aura no alcanza a iluminar. Solo por ese 
"algo" la copia, sigue siendo copia. Es decir, solo por ese "algo" la copia no alcanza a constituirse en la ipseidad del original, toda vez que, como hemos visto, ese original es la ficción de la soberanía y la soberanía de la ficción, donde ésta nunca puede coincidir enteramente consigo misma. El desgarramiento temporal que le difiere vendría a definir a ese "algo" que resiste siempre a la "felicidad del Edén" y que estructura la paradoja de una copia que intenta investirse del original o, lo que es igual, del original "puro" que no deja ser atravesado por la copia que lo constituye. Así, el conflicto de la república será la imposibilidad de constituirse en un original "puro", toda vez que el himno parece llevar consigo un poema que lo desgarra desde dentro, impidiéndole suturar plenamente al régimen de la soberanía.

El poema que desgarra a la arquitectura del himno se despliega con toda su fuerza en la forma de una patria que no tendrá la forma estatal. Pero una patria no estatal que vive no bajo la bandera, sino a pesar de ella, porque sus signos titilan como "seña sutil" -escribe Mistral. Una patria que no tiene himnos sino poemas. Y véase que ésta es la patria secreta que, por serlo, habita en los laberintos del himno. Esa patria no tiene nombre o, más bien, una matria que, como tal, se sustrae a todo nombre.

Quizás haya sido ese lugar sobre el que dio testimonio Mistral en su poema País de la Ausencia:

\section{Nombre suyo, nombre, Nunca se lo oí \\ Y en país sin nombre Me voy a morir.}

El poema marca la distancia entre copia y Edén, interrumpiendo así el movimiento de su articulación, habitando en la inadecuación radical de la propia soberanía. Por ello, la matria de Mistral es generosa. Porque ella no es más que la abertura a todos los nombres posibles. La matria mistraliana es, por tanto, una patria completamente ajena a la patria militar, porque donde ésta última realiza el proyecto teológico-político de la “copia feliz del Edén”, esta lo desactiva en un solo verso.

En este sentido, si la patria militar intenta suturar la distancia entre original y la copia, la patria mistraliana ha cortado el fantasma con el original y, en ello, ha dejado atrás la relación de sujeción. Quizás ésta sea, verdaderamente, la patria de los libres. Porque en ella ya no existe diferencia entre original y copia. Así, el desgarramiento que la soberanía del himno intenta articular a través del adjetivo "feliz" como su operador esencial, es desactivado por el contramovimiento que introduce el poema. Con ello, la lengua se abre como potencia genérica que siendo de todos y, a la vez, de nadie, revoca toda formación soberana. Así, siendo inmanente a la propia operación de la soberanía, en el reverso del propio himno se abre la matria mistraliana que disloca al paradigma angelológico del himno para volcarlo sobre su más íntimo secreto, aquella "edad de siempre /sin edad feliz". 


\section{Excursus 1: Los Sin Nombre}

La arquitectura del himno estructurada sobre la base del triunvirato constituido entre los hombres (la "copia"), los ángeles ("feliz") y Dios (el "Edén”) se refleja en la arquitectura de la conocida Plaza Italia. En ella, la jerarquía antedicha se visibiliza en los hombres que circulan por sus calles (la copia), los militares en la estatua del general Baquedano ("feliz") y los empresarios con el edificio-monumento de Telefónica ("Edén"). Pero, exactamente como ocurre en el himno, la Plaza Italia lleva consigo la irrupción del poema.

El solo hecho de llamarse "Plaza Italia", nombre que designa a una plaza diferente y desplazada hacia un costado de aquella situada al centro de la misma (la "Plaza Baquedano") implica una dislocación de las fuerzas respecto del significante Amo. Así, en la jerarquía hímnica constituida por los civiles, los militares y los empresarios no deja de titilar el contramovimiento del poema. Por ello, como todo espacio verdaderamente público, la Plaza Italia es un campo de lucha que se expresa en la batalla por el nombre. Por esto, el nombre "Plaza Baquedano" impuesto por los vencedores, no deja de diferir una y otra vez respecto del de "Plaza Italia" que le sobrevive internamente.

En este sentido, la pugna entre la Plaza Baquedano y la Plaza Italia reproduce la pugna entre himno y poema que hemos expuesto en el presente texto. En este sentido, la arquitectura del himno y, a la vez, la himnicidad de la arquitectura conforman, pues, los espacios de la ciudad, cuya lucha encuentra en la mentada Plaza su lugar privilegiado.

\section{Excursus 2: EI "huacho" Riquelme}

La arquitectura del himno y el desgarro del poema quizás encuentren su mejor expresión en la figura de quien fue considerado el padre de la patria, don Bernardo O'Higgins, conocido en su tiempo como el "huacho" Riquelme. La diferencia entre el apellido paterno que lleva consigo una impronta de "originalidad", versus el apellido materno que le condena a ser simple "copia" es decisiva a la hora de mirar cómo es que el libertador se volvió un "Director Supremo" y, a su vez, cómo éste, dando un paso al costado, terminó sus días exiliado en el Perú.

Si el conflicto de la República es el de constituir un original desde su propia posición de copia, no puede haber gesto más hiperbólico que aquél que convierte al huacho Riquelme en el Director Supremo don Bernardo O'Higgins: ¿Qué más “feliz” que una copia que accede a la primera magistratura, a la soberanía del original? Pero, a la vez: ¿qué más fallido que dicho acto, que culmina en el exilio del mismo que tenía los máximos poderes? ¿Qué es el máximo y el mínimo poder, qué son, pues, el Edén y la copia, sino dos polos de un mismo campo de tensiones? 
Toda la historia política de O'Higgins revela que los versos "la copia feliz del Edén" son, a la vez, "la copia in-feliz del Edén", porque una vez cumplida la misión, ésta parece fracasar estrepitosamente. Lo "feliz" confirma su jerarquía radicalmente "in-feliz", puesto que lo "in-feliz" indicará el límite que la propia copia pretende vanamente superar. Porque, como hemos visto, dicho fracaso no sería una anomalía a la propia arquitectura del himno, sino su estructura más propia: la soberanía siempre difiere de sí, ella misma no es otra cosa que una copia "feliz" o, lo que es igual, "infeliz", toda vez que nunca logra coincidir enteramente consigo misma. El "huacho" Riquelme o don Bernardo O’Higgins, la copia o el Edén, la lejanía del exilio o la máxima magistratura, respectivamente.

\section{Excursus 3: Notas para una arqueología de la policía en Chile}

La himnicidad de la arquitectura se resuelve integralmente en la configuración de los espacios de la ciudad. En ellos, el conflicto entre himno y poema se articula esencialmente a partir de la función policial. Por esta razón, no es anodino trazar una posible arqueología de la función policial después de los atroces acontecimientos de la dictadura y, a su vez, del incesante despliegue de los mecanismos de seguridad durante la democracia. En este sentido, trazar dicha arqueología me parece que constituye un problema político de primera magnitud.

1.- En el Acta del cabildo del 25 de Abril de 1541 se lee: "Por cuanto al servicio de Dios y S.M. e al bien universal de sus vasallos, conviene haya oficiales y ministros para ejecutar la justicia real en esta ciudad y sus términos, e siendo como es nuevamente poblada, hai necesidad de una persona que ejercite e use el oficio de alguacil mayor, que se hábil es suficiente, temeroso de su conciencia y zeloso del servicio de S.M. " ${ }^{10}$ En dicho cabildo fue nombrado el primer funcionario policial del Reyno de Chile denominado "alguacil mayor". Sería importante subrayar el singular estatuto que rodea a dicho alguacil, según el cual, éste se debe a Dios y S.M. (el lugar de la soberanía) y, por otro, a la efectiva ejecución de la justicia en el orden mundano (el despliegue del gobierno). En este sentido, la función del alguacil consiste en abrir un espacio promiscuo entre una norma trascendente vinculada a Dios y S.M. y un orden inmanente destinado a llevar a cumplimiento la "justicia real en esta ciudad". La clave aquí es que el alguacil mayor está cumpliendo una función estrictamente angelológica toda vez que se sitúa como operador que, recibiendo una orden precisa desde el reino de los cielos, la ejecuta sin dejo de duda en el orden terrenal. Así, la posición del alguacil mayor es igual a aquélla en que está situado el adjetivo "feliz" en los versos hímnicos analizados. 
2.- Con fecha del 19 de Agosto de 1788, Ambrosio O'Higgins exigía la existencia de un Buen Gobierno para "precaver los grandes males": "No 1.- Que nadie sea osado, con pretexto alguno, a decir blasfemias contra Dios Nuestro Señor, la Santísima Virgen María, santos, personas i cosas sagradas, ni a cometer homicidios, robos, desacatos, evitando escándalos (...) para que todos vivan cristiana, honesta i pacificamente, bajo las penas establecidas por las leyes. / No 3.- Que para precaver los grandes males $i$ delitos que facilita $i$ encumbre la soledad $i$ obscuridad de la noche a los malos intencionados, nadie se mantenga arrimado a las puertas, paredes, esquinas, ni nadie en cuadrillas, o a deshoras por las calles o paseos, recogiéndose todos a sus casas (...)'. El dictamen de O'Higgins contiene, al menos, dos elementos a considerar. En primer lugar, el hecho de que el documento escrito previo al proceso independentista prohíbe la blasfemia porque, en la medida en que ésta se define teológicamente por pronunciar el nombre de Dios en vano, exhibe el exceso y la incoincidencia entre las palabras y las cosas. Y allí donde las palabras y las cosas no coinciden, el dispositivo hímnico es dislocado, irrumpiendo así la an-arquía del poema. En segundo lugar, que este documento, teniendo un carácter estrictamente gubernamental, dé cuenta, por vez primera, del discurso de la prevención del delito, cuyo efecto inmediato habría sido el de que los ciudadanos se recojan "todos a sus casas" y, por lo tanto, la esfera pública fuera completamente abandonada. Aquí, la prevención del delito funciona como un garante de la arquitectura del himno, impidiendo, a su vez, la dislocación del poema.

3.- Los albores de la República vieron de la pluma del mismo Diego Portales la organización del cuerpo de la "Policía Vijilante" el 8 de Junio de 1830. Lo novedoso de este documento es que, traspasando su responsabilidad a la Municipalidad de Santiago, éste define bajo nuevos términos a la función policial en cuanto tal: "Policía, que con más vigilancia que hasta aquí, cuide de la seguridad pública, de la decencia de las costumbres i del aseo de la población. " El giro del léxico respecto de aquél utilizado en el cabildo de 1541 o, inclusive, en aquél redactado por Ambrosio O'Higgins, es evidente: surgen los términos "seguridad" y "población" que, como sabemos a partir de los trabajos de Foucault, constituyen una transformación del clásico paradigma del poder basado en la "soberanía jurídica" a un poder que actúa directamente sobre la vida, a un biopoder: "3.o del cumplimiento de todas las disposiciones de policía, de aseo, comodidad y buen órden de la población." Los Vijilantes que Portales tiene en mente parecen proyectarse en una función estrictamente económica que, como tal, ha de resguardar el "buen órden de la población" disponiendo su aseo y su comodidad. Así, quizás podríamos decir que este documento indica cómo es que, desde el principio, el verdadero sujeto de la República de Chile no fue el ciudadano, sino su vida biológica. En este sentido, los Vijilantes de Portales cumplen con la misma función que el adjetivo "feliz" en los versos del himno y, con ello, trazan su arqui-tectura: articular el orden inmanente (la copia) con la norma trascendente (El Edén), suturando así la abertura del poema que se asoma en la incandescente abertura de una multitudo. 


\section{Excursus 4: Los restos de la Gloria}

No es extraño que en Chile los gestos de celebración refieran a materias poco decorosas como las heces. Como si la glorificación de la República comportara una fuerza tal capaz de despertar hasta los más bajos instintos. La fuerza excepcional que caracteriza a la soberanía parece tener tal intensidad que no puede sino exclamarse dejando en ella una suerte de regalo. Como si, en último término, la exaltación de la República tuviese un extraño espíritu coprofílico, en cuya fuerza fuera imposible retener aquello digerido y toda la luz del proceso terminara resolviéndose en la oscuridad de las heces.

Quizás, el dicho "viva Chile, mierda" sea, en este sentido, el exacto reverso del verso hímnico "la copia feliz del Edén", toda vez que testimonia que la "felicidad" a la cual la copia remite lleva consigo una "in-felicidad" estructural, esto es, que por definición, la copia jamás podrá coincidir con el original. "Feliz" es el índice de dicha incoincidencia y, a la vez, la vía que inextricablemente fuerza hacia ella. De esta tensión, entre la felicidad y la in-felicidad que le es inmanente, tiene lugar el desgarro, el exceso de fuerza que, arribando al Edén por un instante, la copia se revela inexorablemente lejana de él. La felicidad de la República coincide, pues, con su infelicidad, lo más bajo con lo más alto, así como el máximo poder se revela como la más profunda impotencia.

Así, solo el esplendor de la gloria parece conducir directamente hacia las heces, toda vez que solo en dicho esplendor la represión es suspendida integralmente. Así, la retención operada por la interdicción de la ley es aflojada y, la copia, que no puede soportar la intensa luz del original, pareciera ofrecer a Dios un singular e indecoroso regalo, diciéndole: "Este poema lo escribo para alabarte".

\section{Referencias bibliográficas}

Agamben, Giorgio (2008), El Reino y la gloria. Una genealogía teológica de la economía y del gobierno. Buenos Aires: Ed. Adriana Hidalgo.

Agamben, Giorgio y Emanuele Coccia, eds. (2009), Angeli. Hebraismo, cristanesimo, islam. Ed. Neri Pozza.

Coccia, Emanuele (2008), Filosofía de la Imaginación. Averroes y el averroísmo. Buenos Aires: Ed. Adriana Hidalgo.

Cristi, Renato (2000), El Pensamiento Político de Jaime Guzmán. Autoridad y Libertad. Santiago de Chile: Ed. Lom.

Foucault, Michel (2006), Seguridad, Territorio, Población. Buenos Aires: Ed. Fondo de Cultura Económica.

Foucault, Michel (2007), El Nacimiento de la biopolítica. Buenos Aires: Ed. Fondo de Cultura Económica.

García de la Huerta, Marcos (2003), Pensar la política. Santiago de Chile: Ed. Sudamericana.

Gonzáles, José María (1998), Metáforas del poder. Madrid: Ed. Alianza. 
Lacoue-Labarthe, Phillipe (2002), La ficción de lo político. Madrid: Ed. Arena Libros. Peri Fagerstrom, René (1982), Apuntes y Transcripciones para una Historia de la función policial en Chile. Santiago de Chile: Ed. Carabineros de Chile, Imprenta. Tomos I, II y III. 